\title{
Correction to: Application of actinidin as coagulants to produce Iranian white brined cheese: investigating the technological, textural, and sensorial properties
}

\author{
Amin Mahdian Dehkordi ${ }^{1} \cdot$ Mahmoud Rezazadeh Bari $^{1}\left[\right.$. Ghobad Babaie ${ }^{2} \cdot$ Saber Amiri $^{1}$
}

Accepted: 4 December 2021 / Published online: 19 December 2021

○) Springer Science+Business Media, LLC, part of Springer Nature 2021

\section{Correction to: \\ Journal of Food Measurement and Characterization https://doi.org/10.1007/s11694-021-01219-8}

In this article the affiliation details of co-author Dr. "Ghobad Babaie" were incorrectly given as "Plant Protection Department, Chaharmahal-Va-Bakhtiari Research Centre for Agriculture and Natural Resources, Shahrekord, Iran' but should have been 'Plant Protection Research Department, Chaharmahal and Bakhtiari Agricultural and Natural Resources Research and Education Centre, AREEO, Shahrekord, Iran'. The original article has been corrected.
Publisher's Note Springer Nature remains neutral with regard to jurisdictional claims in published maps and institutional affiliations.

The original article can be found online at https://doi.org/10.1007/ s11694-021-01219-8.

Mahmoud Rezazadeh Bari

m.rezazadehbari@urmia.ac.ir

$\triangle$ Saber Amiri

sa.amiri@urmia.ac.ir

1 Department of Food Science and Technology, Faculty of Agriculture, Urmia University, P.O. Box 57561-51818, Urmia, Iran

2 Plant Protection Research Department, Chaharmahal and Bakhtiari Agricultural and Natural Resources Research and Education Centre, AREEO, Shahrekord, Iran 